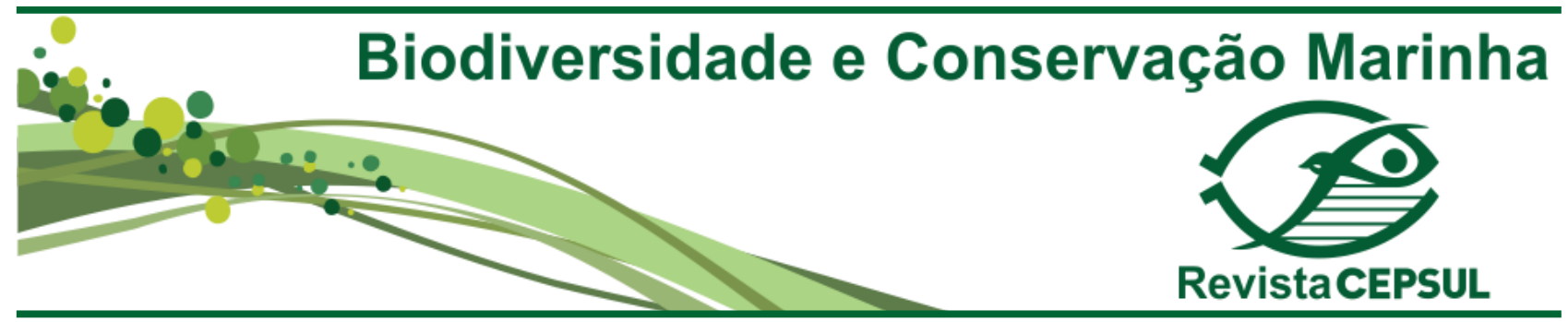

ARTIGO

\title{
Até onde posso arrastar? - Construindo acordos sobre os limites da pesca artesanal de arrasto na Baía Norte de Florianópolis frente à legislação ambiental.
}

\author{
Walter Steenbock1, Roberta Aguiar dos Santos¹, Heitor Schulz Macedo², Edson Gracindo
}

de Almeida ${ }^{2}$, Marcos Cesar da Silva², Rodrigo Pereira Medeiros³, Eloisa Pinto Vizuete ${ }^{1}$

${ }^{1}$ Centro Nacional de Pesquisa e Conservação da Biodiversidade Marinha do Sudeste e Sul - CEPSUL/ICMBio, Av. Ministro Victor Konder, 374, CEP - 88301-70o, Itajaí, SC, Brasil, walter.steenbock@icmbio.gov.br , roberta.santos@icmbio.gov.br, eloisa.vizuete@icmbio.gov.br;

2 Área de Proteção Ambiental de Anhatomirim - APA Anhatomirim/ICMBio, Rod. Maurício Sirotsky Sobrinho, km 2 , Jurerê, CEP 88053-70o, Florianópolis, SC, Brasil, heitor.macedo@icmbio.gov.br, edson.almeida@icmbio.gov.br, marcoscesar.silva@icmbio.gov.br;

${ }_{3}^{3}$ Centro de Estudos do Mar - CEM, Universidade Federal do Paraná - UFPR, Av. Beira-mar, s/n, Pontal do Sul, CEP - 83255-976, Pontal do Paraná, PR, Brasil, rodrigo.medeiros@ufpr.br.

Resumo. A região marinha entre o norte da Ilha de Santa Catarina e o continente, em Santa Catarina, tem sido considerada pelos órgãos de fiscalização ambiental como uma baía e, portanto, como área de restrição à pesca de arrasto de camarões, de acordo com a Portaria $\mathrm{n}^{\circ}$ 51/83, da extinta Superintendência do Desenvolvimento da Pesca (SUDEPE). Essa Portaria, que permanece válida, proíbe essa modalidade de pesca em baías do Estado, mas não define o limite geográfico dessas baías, tornando legalmente insegura a atividade de centenas de pescadores artesanais da região. $\mathrm{O}$ debate sobre a determinação dos limites da chamada "Baía Norte" de Florianópolis foi incrementado a partir da construção participativa do Plano de Manejo da Área de Proteção Ambiental do Anhatomirim (APAA), publicado em 2013. Em setembro de 2014, pescadores artesanais de arrasto de camarões foram autuados pelo Instituto Brasileiro de Meio Ambiente e Recursos Naturais Renováveis (IBAMA), por estarem pescando dentro dos limites da "Baía Norte", muito embora os pescadores estivessem fora destes limites, considerando tanto os limites usualmente praticados pela Polícia Ambiental de Santa Catarina quanto a proposição deste limite pelo Plano de Manejo da APAA. O episódio deflagrou a mobilização dos pescadores para a institucionalização da definição deste limite, durante a qual foram realizadas reuniões em diferentes fóruns e elaborados vários documentos técnicos, subsidiando um acordo sobre o limite em questão, envolvendo pescadores e órgãos ambientais, dentre outras agências governamentais, em novembro de 2014. Neste artigo, apresentamos os resultados do acompanhamento das reuniões realizadas neste período e da análise dos documentos técnicos produzidos, bem como uma discussão em torno dos aspectos sociais, ambientais e institucionais relativos à aplicabilidade da legislação ambiental. 
Palavras-chave: Pesca artesanal; Unidade de Conservação; Legislação ambiental; APA do Anhatomirim.

\begin{abstract}
Till where can we trawl? - Building agreements on the limits of traditional trawling of Florianopolis' North Bay front of environmental legislation. The sea region between the northern part of Santa Catarina Island and the mainland, in Santa Catarina State/Brazil, has been considered for environmental monitoring institutions as a bay and therefore a restriction area to shrimp trawling, according to what defines a policy (Portaria $n^{\circ}{ }^{1} 1 / 83$ ) of the extint Superintendence for Fisheries Development (SUDEPE). This policy defines the prohibition of this kind of fishing in the bays of Santa Catarina, but does not define the geographical boundary of these bays, making legally insecure the activity of hundreds of artisanal fishermen at the region. The debate on the determination of the called "Florianópolis North Bay" limits was increased from the participatory development of the Management Plan of the Environmental Protection Area of Anhatomirim (APAA), published in 2013. In September 2014, artisanal fishermen of shrimp trawling were fined by IBAMA, for fishing within the limits of the bay, even though the fishermen were out of those limits, considering both the limits usually practiced by the Environmental Police of Santa Catarina and the limit proposed by the APA Management Plan. The episode triggered the mobilization of fishermen to the institutionalization of this limit, during which meetings were held in various forums and were prepared several technical documents, supporting an agreement on the limit in question, involving fishermen and environmental and other governmental agencies in November 2014. In this paper, we followed the meetings held during this period and analyzing the technical documents produced, discussing social, environmental and institutional aspects regarding the applicability of environmental legislation.
\end{abstract}

Key words: Artisanal Fishing, Protected Areas, Environmental Legislation, APA of Anhatomirim

\section{Introdução}

A legislação ambiental institucionalizou por meio da Portaria SUDEPE ${ }^{\circ} 51 / 83$ (Brasil, 1983a), "a proibição da pesca de arrasto sob qualquer denominação, em baías, lagoas costeiras, canais e desembocaduras de rios (estuários)", no Estado de Santa Catarina.

Muito embora a SUDEPE (Superintendência do Desenvolvimento da Pesca) ter sido extinta, quando da criação do Instituto Brasileiro de Meio Ambiente e Recursos Naturais Renováveis (IBAMA), em 1989, esta Portaria não foi cancelada ou suprimida por nenhum outro ato normativo até o presente momento, pelos atuais órgãos competentes. Elaborada a partir de recomendações do Grupo Permanente de Estudos sobre Camarões (Brasil, 1983b), que assessorava a SUDEPE à época, esta norma teve como objetivo reduzir o impacto da pesca de arrasto sobre ambientes considerados críticos para algumas espécies, como o caso de áreas de criadouros naturais.

Porém, a referida Portaria não definiu claramente quais os limites das "baías" e "canais". Assim, sua aplicação ficou a critério de cada órgão de fiscalização, a partir de seus entendimentos, que foram alterando durante mais de 30 anos após sua elaboração. Paralelamente, foram editadas, ao longo do tempo, outras normas de ordenamento territorial e da pesca e criadas novas áreas marinhas protegidas (com seus respectivos zoneamentos e programas) no litoral de Santa Catarina, tornando por vezes complexa a implementação efetiva da Portaria SUDEPE $n^{\circ} 51 / 83$.

O relatório da quarta reunião do Grupo 
Permanente de Estudos sobre Camarões, ocorrido em setembro de 1983, na cidade de Santos (SP), indica a motivação da Portaria SUDEPE $\mathrm{n}^{\circ}$ 51/83. Resumidamente, este relatório foi baseado em estatísticas pesqueiras e na biologia das principais espécies de camarão capturadas, embora tenha se concentrado no camarãorosa, cujo ciclo de vida compreende desova no oceano, migração das larvas para as áreas lagunares (zonas de criação) e, como pré-adultos, retorno ao oceano para completar seu ciclo. A captura, segundo o relatório, ocorria então distintamente: a população jovem era capturada pela pesca artesanal e a população adulta pela pesca industrial. Nas regiões Sul e Sudeste, observou-se decréscimo nas pescarias em anos anteriores, tanto da pesca industrial como da pesca artesanal. No ano de 1967, é introduzida a moderna frota industrial e que, em 1969, atinge sua produção máxima de camarão-rosa adulto com 7.102 toneladas, para, no ano de 1973, entrar em colapso (entre 2.300 e 3.300 toneladas). No mesmo período, registra-se, principalmente em Santa Catarina, aumento acentuado na captura de juvenis pela pesca artesanal e que se estende até o ano de 1980 (de 1.600 toneladas em 1973 alcançou 9.300 toneladas em 1979), mas também apresentando declínio logo após.

O Grupo concluiu que a exploração nos criadouros estava afetando a recomposição do estoque adulto do camarão-rosa, por impedir que os juvenis migrassem para completar seu ciclo de vida no oceano (p. 16) e não existia maneira prática e eficaz de adotar o defeso em áreas específicas e/ou de restringi-lo ao camarão -rosa, porque a frota atuava em toda a área e a composição da captura do mesmo incluía as outras espécies (p. 18).

Dessa forma, a norma definida proibiu o arrasto motorizado de qualquer espécie de camarão, dentro dos acidentes geográficos que menciona, sem, contudo, detalhar onde começam e terminam esses espaços restringidos. Isso, no caso da região de Florianópolis e municípios próximos, gerou controvérsias e incer- tezas, que bem ou mal vêm se resolvendo conforme a interpretação conferida à norma ou à própria identificação dos mencionados espaços de restrição, como fator preliminar.

Mais especificamente, o território em análise neste estudo situa-se entre o continente e a Ilha de Santa Catarina, na denominada "Baía Norte", área de tradicional uso de pescadores de arrasto da frota artesanal. Nos últimos anos, a Polícia Ambiental de Santa Catarina vinha assumindo como limite, para fins de fiscalização, uma linha imaginária formada entre o forte de Santa Cruz, na Ilha de Anhatomirim (próxima ao continente), e o forte de São José da Ponta Grossa (na parte insular de Florianópolis), muito embora esse limite não estivesse acordado entre os demais órgãos ambientais e instituições relacionadas ao ordenamento territorial na região, e nem entre os pescadores (Figura 1). Assim, nessa região, o arrasto motorizado de camarão poderia existir legalmente ou não, a depender da interpretação dada ao que seja baía e definindo-se sua localização e abrangência.

A questão dos limites da Baía Norte de Florianópolis foi resgatada durante a elaboração do Plano de Manejo da Área de Proteção Ambiental do Anhatomirim (APAA), publicado em 2013. A APAA é uma unidade de conservação federal que abrange região marinha e terrestre do município de Governador Celso Ramos (SC). Sua parte marinha abrange 1,5 milhas, na área da suposta Baía Norte. A Unidade foi criada em 1992, com o objetivo de "assegurar a proteção da população residente de golfinhos, bem como os remanescentes de mata atlântica e fontes hídricas de relevante interesse para a sobrevivência das comunidades de pescadores artesanais da região" (Brasil, 1992). (Figura 2).

No processo de elaboração de seu Plano de Manejo, com debates por cerca de três anos junto aos pescadores artesanais, principalmente do município de Governador Celso Ramos, a APAA recolheu histórias desde o tempo em que 


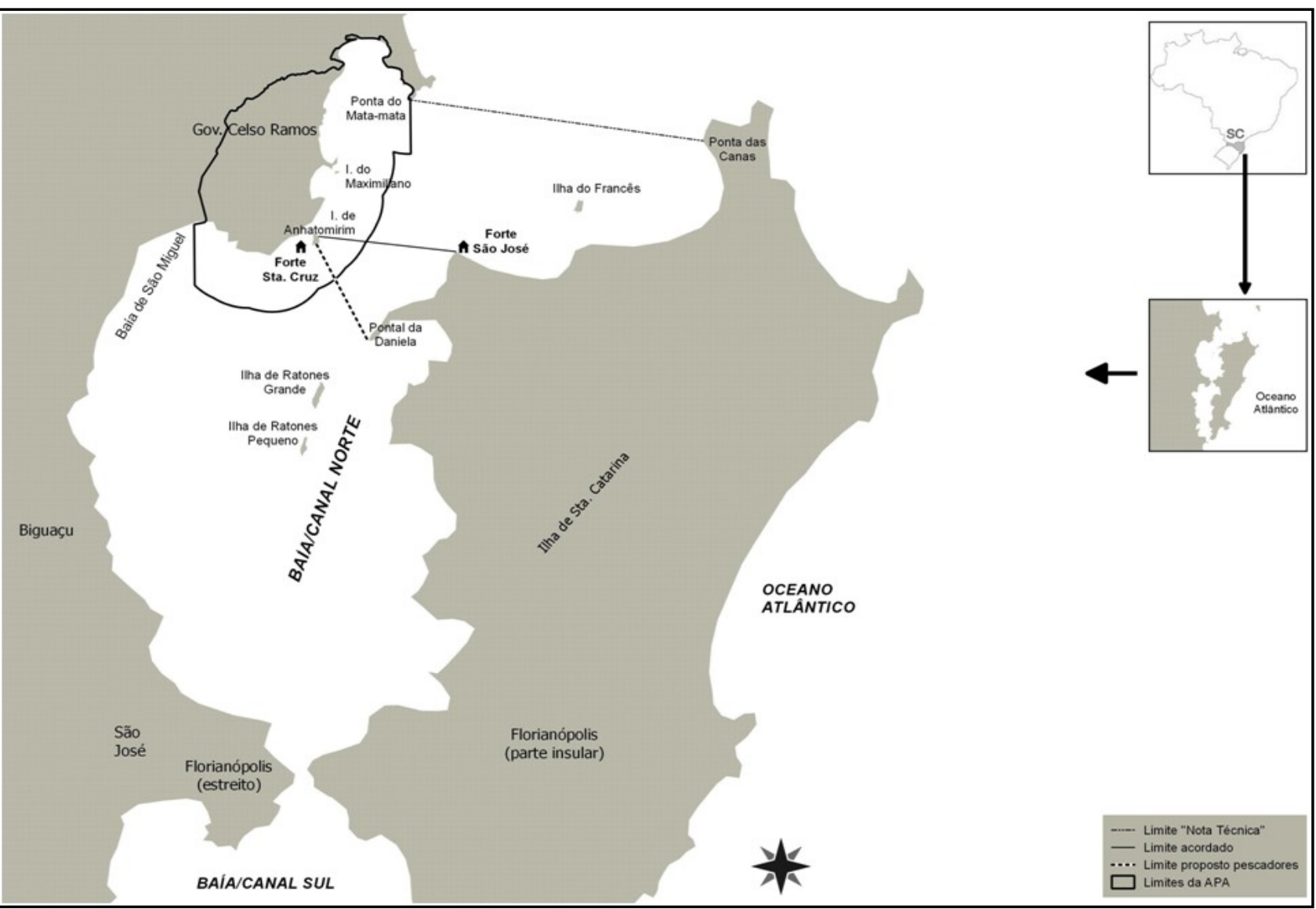

Figura 1. Proposições de limites da pesca de arrasto na "Baía Norte de Florianópolis", a partir da proposta dos pescadores artesanais de arrasto e do Plano de Manejo da APAA, da Nota Técnica do Núcleo de Licenciamento Ambiental do IBAMA-SC e do Acordo construído entre os pescadores e instituições da região em 2014, consonante com o limite que vinha sendo utilizado pela Polícia Ambiental de Santa Catarina, para fins de fiscalização.

não havia limites territoriais para o arrasto camaroneiro na Baía Norte até o advento da Portaria SUDEPE $\mathrm{n}^{\circ}$ 51/83; aliás, nesses relatos, era forte a discordância em chamar de "baía" o espelho d'água marítimo que separa o continente da parte insular da capital catarinense (mencionava-se inclusive que a carta náutica da Marinha registra os nomes "canal sul" e "canal norte", tendo como divisor a ponte ou pontes rodoviárias entre ilha e continente). Com a Portaria, iniciou-se a prática de impor limites ao arrasto, por parte dos órgãos ambientais com atuação na região. Neste processo, nunca se fechou totalmente a chamada Baía Norte aos arrasteiros, mas pouco a pouco foi se reduzindo sua área, à medida que os referenciais da linha imaginária desse limite foram sendo estabelecidos cada vez mais ao norte.
Também no Plano de Manejo da APAA, na porção marítima da Unidade, acordou-se como linha imaginária limítrofe do arrasto um ponto entre o extremo sudeste da Ilha do Anhatomirim até seu encontro com os limites da Unidade no mar; no debate, então, vislumbrouse a possibilidade de essa linha estender-se até alcançar a Ilha de Santa Catarina, no pontal da praia da Daniela, a depender de um pacto com os pescadores artesanais usuários do território pesqueiro ali. Dentro da APAA, de fato, ampliou-se o limite de arrasto permitido. Isso decorreu do processo de discussão e elaboração participativa do Plano de Manejo, o que permitiu a articulação de um grupo representativo de pescadores artesanais na modalidade de arrasto motorizado, liderados por integrantes jovens e mais capitalizados, mas também por integran- 


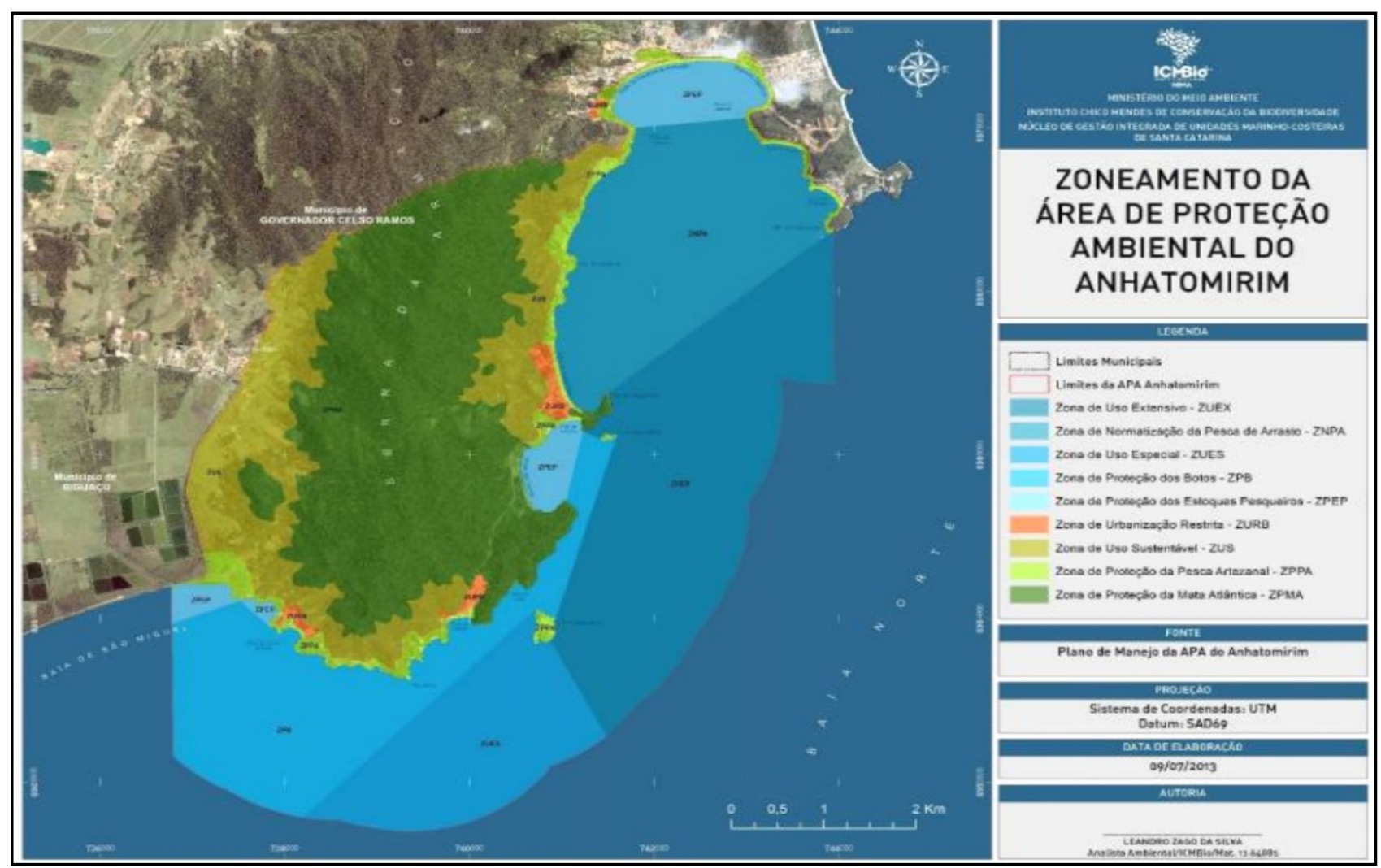

Figura 2. Mapa de Zoneamento da APA do Anhatomirim, conforme Plano de Manejo (2013). Fonte: Brasil (2013a).

tes de mais idade e bastante contrafeitos com as restrições de área de pesca ao longo dos anos. Em verdade, a esse grupo interessava ampliar a área além da porção da APAA, porquanto o ganho havido dentro da Unidade recaiu em uma faixa com uma laje de pedra, onde a pesca não é viável.

Nesse canal ou baía, como se queira, as correntes marítimas deslocam-se no sentido norte-sul, e vice-versa, banhando um conjunto de enseadas, baías e desembocaduras, localizadas tanto em Florianópolis como nos municípios vizinhos. Tomando por referência a Ilha de Santa Catarina, o último limite do arrasto, segundo os relatos e conforme antes mencionado, foi de "forte a forte", ou do forte de São José ao forte de Santa Cruz (Figura 1). Essa noção de limite existia, em maior ou menor grau, entre pescadores e a fiscalização, principalmente da Polícia Ambiental.

Em setembro de 2014, entretanto, pescadores artesanais de arrasto foram autuados pelo IBAMA, por estarem pescando, de acordo com os autos de infração, dentro dos limites da Baía Norte de Florianópolis, portanto em desacordo com a Portaria SUDEPE $n^{0} 51 / 83$. Segundo os pescadores, porém, eles foram abordados acima do limite definido da Baía Norte, considerando tanto o limite proposto pelo Plano de Manejo da APAA quanto o que vinha sendo aplicado pela Polícia Ambiental.

O episódio deixou claro que o limite proposto durante as discussões do Plano de Manejo da APAA não estava plenamente aceito nem entre os órgãos ambientais, deflagrando um processo de mobilização dos pescadores artesanais de arrasto e uma nova e amplificada discussão sobre os limites da Baía Norte. Esse processo envolveu, além dos pescadores, a equipe da APAA, outros representantes do ICMBio (Coordenação Regional-CR9, Centro Nacional de Pesquisa e Conservação da Biodiversidade Marinha do Sudeste e Sul-CEPSUL, Estação Ecológica (ESEC) Carijós e Reserva Biológica (REBIO) Arvoredo), do IBAMA, da Polí- 
cia Ambiental de Santa Catarina, da Polícia Federal, do Ministério Público Federal e do Ministério da Pesca e Aquicultura, os quais participaram em diferentes momentos e com diversos graus de envolvimento, desde reuniões, audiências judiciais, produção de documentos, até se celebrar um acordo no auditório da Ordem dos Advogados do Brasil (OAB) em Florianópolis.

Este trabalho procurou analisar a construção deste acordo, desde a emissão dos autos de infração ocorrida em 2014.

\section{Materiais e métodos}

Foram acompanhadas as reuniões entre pescadores, autoridades ambientais e pesquisadores, entre setembro e novembro de 2014, realizadas no sentido de construir o acordo sobre o limite geográfico da pesca artesanal de arrasto de camarões, na chamada Baía Norte de Florianópolis.

Analisamos também, além do Plano de Manejo da APAA, documentos técnicos elaborados nesse período, de autoria da APAA, da Estação Ecológica (ESEC) de Carijós e do Núcleo de Licenciamento Ambiental do IBAMASC, que visavam subsidiar definições sobre os limites da pesca de arrasto motorizado.

Os resultados foram descritos seguindo a ordem cronológica dos fatos, mesclando informações concernentes às reuniões com informações provenientes dos documentos técnicos citados.

\section{Resultados}

\section{O arrasto de fundo na APAA e o seu Pla- no de Manejo}

O plano de manejo é o principal instrumento de gestão de uma unidade de conservação, sendo definido como o "documento técnico mediante o qual, com fundamento nos objetivos gerais de uma unidade de conservação, se estabelece o seu zoneamento e as normas que devem presidir o uso da área e o manejo dos recursos naturais, inclusive a implantação das estruturas físicas necessárias à gestão da unidade", devendo ser construído de forma a "assegurar a ampla participação da população residente" (Brasil, 2000). Neste sentido, inclusive, é fundamental que o conselho da unidade de conservação venha a "acompanhar a elaboração, implementação e revisão do Plano de Manejo" (Brasil, 2002a)

Seguindo estes princípios, o Plano de Manejo da APAA foi fruto de um processo caracterizado por grande participação social, especialmente dos pescadores artesanais. De acordo com o documento, "esses atores foram considerados prioritários no processo de elaboração do Plano de Manejo, pois são um dos objetivos de criação da APAA e até então vinham sendo historicamente excluídos dos processos decisórios de gestão da UC" (Brasil, 2013).

O Plano de Manejo da APAA veio a estabelecer regramentos a partir de acordos sociais, especialmente em relação ao zoneamento da Unidade. Entre estes regramentos, foi definida a Zona de Normatização da Pesca de Arrasto (ZNPA), área marinha ecologicamente sensível, mas utilizada pelos pescadores artesanais (Figura 2). Nesta zona, uma das ações gerenciais definidas foi o "estímulo a alternativas técnicas ou tecnológicas de mitigação dos impactos das atividades antrópicas, com destaque à pesca de arrasto". Entre as normas estabelecidas para esta zona, definiu-se que "a pesca de arrasto estará sujeita também a normativas decorrentes de experimentos conjugando o saber técnico-científico e o tradicional, visando estabelecer estratégias menos predatórias.” (Brasil, 2013).

Com base nestas normas e ações gerenciais, vem sendo implementado um projeto de pesquisa participante com pescadores artesanais da frota de arrasto da APAA, visando à construção de uma rede de experimentação, diálogo e aprendizagem, a fim de estimular a adoção voluntária de dispositivos tecnológicos 
para a redução da fauna acompanhante, ou seja, de indivíduos de espécies da fauna não alvos da pescaria, pescados incidentalmente (BRD, na sigla em inglês de bycatch reduction device, ou dispositivo redutor de fauna acompanhante). Basicamente, o projeto tem tratado de testar variações tecnológicas nas redes (BRDs), avaliando sua eficácia para a pesca do camarão e, ao mesmo tempo, para a redução da fauna acompanhante. Os resultados parciais têm sido discutidos com os pescadores, em diferentes fóruns (Vessaz, 2014; Portella, 2015).

Conforme já citado, durante o processo de construção do Plano de Manejo, os pescadores apontaram a necessidade urgente de discutir e propor os limites da pesca de arrasto na denominada Baía Norte de Florianópolis, agregando conhecimentos técnicos e tradicionais e considerações dos órgãos ambientais, do patrimônio da união e de direitos difusos (IBAMA, ICMBio, FATMA, Marinha, Capitania dos Portos, SPU e MPF). Após uma série de debates sobre o tema, foi proposto um limite por uma linha imaginária formada entre a Fortaleza de Anhatomirim, no continente, e o Pontal da Daniela (Figura 1).

Muito embora essa proposição de limite tenha sido originada do processo de discussão e geração de acordos do Plano de Manejo da APAA, a linha limítrofe proposta extrapola o território da Unidade, o qual está sujeito a outras esferas e normas de ordenamento. Porém, considerando a ampla participação dos órgãos citados - responsáveis pelo cumprimento do ordenamento também fora do território da APAA - é possível afirmar que se buscou, durante a elaboração do documento, um consenso para a aplicação geográfica do que propõe a Portaria SUDEPE $n^{0} 51 / 83$, na região como um todo.

Cabe ressaltar, todavia, que tal limite não foi proposto apenas por pescadores artesanais de arrasto, mas também por pescadores artesanais de outras modalidades (especialmente caceio), além de técnicos, pes- quisadores, gestores e membros da comunidade no território da APAA.

Entretanto, para outras modalidades de pesca, especialmente a de caceio de camarão, o posicionamento não era plenamente favorável a ampliar a área de arrasto motorizado, por conflito de território e pela desvantagem comparativa (no caceio, a rede segue sozinha com a força da corrente, enquanto no arrasto ela é puxada pelo barco a motor). Dentre os pescadores de caceio, aqueles que também praticavam o arrasto é que assentiam com o aumento da área. Portanto, é importante considerar aqui que o limite proposto, apesar de bastante discutido entre os pescadores, não era totalmente aceito entre os pescadores das diferentes modalidades, e nem produto final de uma discussão baseada em critérios técnicos ou do conhecimento tradicional.

De qualquer forma, a proposição do limite no Plano de Manejo foi considerada uma vitória pelos pescadores artesanais de arrasto, pois o limite aplicado pela fiscalização, como já descrito, era entre a Fortaleza de Anhatomirim e o Forte São José da Ponta Grossa (na Ilha de Santa Catarina), portanto mais ao norte e, consequentemente, mais restritivo (Figura 1).

Considerando que esses limites propostos vão além do território desta unidade de conservação, o Plano de Manejo estabelece que estes constituem uma proposta, a qual deveria ser negociada em momento posterior, envolvendo também outros atores interessados, em especial do outro lado da Baía Norte, ou seja, dos pescadores residentes na Ilha de Santa Catarina.

Assim, apesar de gestionado, permaneceu o conflito em relação ao limite da pesca de arrasto, o qual é incrementado por diversos fatores, entre os quais se destacam os seguintes: parte do território utilizado pela pesca de arrasto também é utilizado pela pesca de caceio, disputando espaço e recursos (camarão); na construção do Plano de Manejo da APAA, houve grande participação de pescadores do muni- 
cípio de Governador Celso Ramos, onde a Unidade está inserida, mas praticamente não houve participação de pescadores da Ilha de Santa Catarina, que também utilizam a região para a pesca; há um aumento crescente do número de embarcações de arrasto na região, assim como do tamanho do motor das mesmas e, portanto, do poder de pesca; as embarcações se caracterizam como de águas interiores, que não podem, portanto, ir para regiões mais abertas ao norte, restringindo sua atuação e aumentando a pressão sobre a região; uma grande quantidade de pescadores de arrasto respeitam o limite definido e reclamam daqueles que o desrespeitam, havendo entretanto um grupo também numeroso (estimado em cerca de 60 embarcações), e crescente, que adota estratégias para burlar a fiscalização realizando, por exemplo, o arrasto na área proibida somente à noite ou ainda avisando às embarcações de arrasto quando qualquer um dos órgãos de fiscalização está no mar; finalmente, a fiscalização (pelos diferentes órgãos responsáveis), ainda que bem intencionada e fruto de grande esforço, é ineficiente e tem sido considerada contraditória ou inadequada por grande parte dos pescadores, ao longo de décadas, gerando relações de desconfiança e receio.

\section{Conflito de 2014 - afinal qual o limite para a pesca artesanal de arrasto na Baía Norte e qual a natureza (geográfica, eco- lógica ou social) deste limite?}

No início do mês de setembro de 2014, seis pescadores artesanais de arrasto de camarões do município de Governador Celso Ramos foram autuados pelo IBAMA, por estarem pescando, de acordo com os autos de infração, dentro dos limites da "Baía Norte de Florianópolis", ou seja, em desacordo com a Portaria SUDEPE $n^{0} 51 / 83$.

No mesmo dia, estava em atuação na APAA uma equipe de servidores da Unidade. Esta foi abordada por alguns pescadores de arrasto requerendo "uma reunião urgente". A reunião ocorreu poucas horas depois e nela, os pescadores manifestaram-se indignados com a autuação, visto que segundo eles os barcos autuados encontravam-se fora de todos os históricos entendimentos e definições sobre os limites da Baía Norte.

Conforme relatado pelos pescadores, os fiscais do IBAMA, no momento da autuação, solicitaram que os mesmos se apresentassem na sede do IBAMA, em Florianópolis, dois dias depois, para os encaminhamentos processuais relativos aos autos. A orientação da equipe da APAA foi justamente neste sentido, recomendando também que os pescadores apontassem aos fiscais a localização georreferenciada dos barcos, bem como a referência do limite proposta a partir do Plano de Manejo da Unidade.

Após a argumentação dos pescadores junto ao IBAMA, contando com os limites definidos no Plano de Manejo, os autos em relação à zona de pesca não foram mantidos, não sendo instaurados processos administrativos e penais.

Entretanto, em julho de 2014, por motivação do Ministério Público Federal (MPF), havia sido elaborada pelo Núcleo de Licenciamento Ambiental do IBAMA/SC a Nota Técnica $\mathrm{n}^{0}$ 02026.000007/2014-72, para o esclarecimento quanto ao limite para aplicação da Portaria SUDEPE $n^{0}$ 51/83 (embora a mesma não tivesse sido ratificada pelo Superintendente do IBAMA/SC e encaminhada oficialmente, até a data da autuação, ao MPF).

Esta Nota Técnica teve por escopo "a análise dos conceitos legais de mar territorial, baía, lagoas costeiras, canais e estuários, bem como competências atuais para gestão dos recursos pesqueiros (...), para fins de definição dos limites espaciais para aplicação da Portaria SUDEPE $\mathrm{n}^{\circ}$ 51/83, nas denominadas "baías norte e sul da Ilha de Santa Catarina" ou "baía de Florianópolis".

A citada Nota Técnica toma como referência a definição geográfica de baía da Convenção das Nações Unidas sobre o Direito do 
Mar, concluída em Montego Bay/Jamaica, em 1982.

Com base especialmente em cálculos geométricos decorrentes desta definição, é feita a caracterização da região entre a Ilha de Santa Catarina e o continente como baía, identificando-se também seus limites norte e sul. O limite norte da baía, descrito na Nota Técnica, fica bem mais ao norte do que o limite definido no Plano de Manejo (Figura 1). Nesse documento, entretanto, não foram considerados fundamentos hidrológicos, como por exemplo a hidrodinâmica marinha, com fluxos de corrente nas direções norte e sul, e vice-versa.

Preocupados com a proposição de limites definida na Nota, os pescadores artesanais de arrasto solicitaram nova reunião com a equipe da APAA, visando esclarecimentos quanto à questão.

Nesta reunião, a posição marcante dos pescadores foi de desconfiança em relação ao alcance do Plano de Manejo da APAA, o qual, construído de forma participativa, não era suficiente para legitimar a proposição dos limites da Baía, tampouco para de fato servir como referência ao IBAMA. Ao mesmo tempo houve manifestações de revolta em face da vulnerabilidade da atividade frente à fragilidade do ordenamento territorial.

A equipe da APAA se comprometeu a discutir a questão junto à Superintendência do IBAMA em Santa Catarina, envolvendo também outras unidades do ICMBio e sua Coordenação Regional no sul do Brasil (CR9), bem como o Ministério Público Federal, o então Ministério da Pesca e Aquicultura (MPA) e a Prefeitura de Governador Celso Ramos, em uma reunião com os pescadores.

Esta articulação culminou com a realização de uma reunião na comunidade da Costeira, no município de Governador Celso Ramos, 20 dias depois, com a presença de autoridades como: o gestor da APAA, o coordenador regional do ICMBio, o prefeito municipal, o superintendente do IBAMA em Santa Catarina e o superintendente do então MPA em Santa Catarina, além de mais de 200 pescadores.

A postura do ICMBio, manifestada tanto pelo gestor da APAA quanto pelo coordenador regional, manteve-se em reforçar a importância de se considerar os limites propostos no Plano de Manejo, devido ao grande acúmulo de discussões e referências trazidas à discussão durante sua elaboração.

O ICMBio trouxe à discussão a importância dos experimentos com BRDs, visando à redução da fauna acompanhante no arrasto artesanal de camarões, contextualizando a necessidade da continuidade e ampliação do monitoramento participativo para o aprimoramento gradativo dos limites da Baía.

De acordo com o então representante do MPA em Santa Catarina, seria importante levar a questão à Comissão Técnica de Gestão Compartilhada dos Recursos Pesqueiros (CTGP), fórum responsável pelas discussões e elaboração de propostas para o ordenamento pesqueiro, sendo coordenadora das atividades do sistema de gestão compartilhada entre o MPA e o MMA (Ministério do Meio Ambiente). Entretanto, reconheceu a necessidade de estimular a sustentabilidade da pesca artesanal e a dificuldade operacional da CTGP, a qual, desde a sua criação, em 2009, tem sido pouco eficaz para promover adequações de ordenamento territorial e pesqueiro locais, em virtude da imensa demanda de situações já existentes em nível nacional.

Na manifestação do IBAMA, referenciou-se igualmente a pertinência de encaminhar a demanda à CTGP. O superintendente do órgão colocou a importância social e econômica da pesca artesanal e a orientação que vem sendo dada no IBAMA para a fiscalização de grandes impactos da pesca (especialmente da pesca industrial) sobre a biodiversidade, deixando claro também que Nota Técnica $n^{0}$ 02026.000007/2014-72, elaborada no Núcleo de Licenciamento Ambiental do IBAMA/SC, não havia sido ainda ratificada na Superinten- 
dência do órgão.

\section{Proposta de Acordo}

Considerando a importância de discutir as diferentes propostas de limite da pesca de arrasto na Baía Norte de Florianópolis, visando como produto o comprometimento entre os envolvidos de estabelecer um acordo sobre a questão, ficou encaminhada a realização de um seminário, que viesse a agregar, além das instituições presentes, o Ministério Público Federal, a Marinha, a SPU, a Polícia Ambiental e a Polícia Federal, bem como pescadores da APAA e dos municípios vizinhos, incluindo Florianópolis.

A equipe da APAA comprometeu-se a mobilizar os atores sociais para o Seminário, a ocorrer no início de novembro de 2014, e a Coordenação Regional do ICMBio a convidar formalmente os participantes.

Durante este período, foi elaborado o Documento Técnico $n^{0} 138 / 2014$, pela ESEC Carijós, trazendo novos elementos e análises ao tema. Este Documento, após ampla argumentação, aponta para a necessidade do entendimento "de que o uso de habitats estuarinos e oceânicos pelos organismos marinhos se dá num gradiente contínuo de condições ambientais (Able, 2005), não reconhecendo fronteiras arbitradas pelo homem, tais como o "limite geográfico" de uma baía, ou a linha imaginária que delimita uma UC", propondo que "a situação posta indica urgência em se estabelecer um "limite de gestão" para a aplicação da veda de pesca de arrasto na Baía Norte, e que este limite não necessariamente deve guardar coincidência com um "limite geográfico", mesmo este baseado nos melhores critérios geográficos disponíveis", e que, "no caso em tela, não é a Geografia que deve subsidiar o processo decisório, mas a Ecologia, ciência natural única capaz de prever e compreender os efeitos das decisões antrópicas sobre a dinâmica das populações e a estrutura das comunidades bióticas, na devida escala de tempo em que se desenrolam" (Brasil,
2014). Com base nesta perspectiva e após propor diferentes cenários de análise, o citado documento afirma que o limite atualmente utilizado para a pesca de arrasto ("de Forte a Forte") na região coincide com o limite norte da Área de Influência da ESEC Carijós e da Área de Interesse para a implantação da Zona de Amortecimento de Carijós, conforme o Plano de Manejo da Unidade (Brasil, 2010), apontando a possibilidade de concordância com o citado limite e indicando a importância da realização de ações de pesquisa e monitoramento na área.

O "Seminário para discussão dos limites da pesca artesanal de arrasto de camarão na Baía Norte de Florianópolis" ocorreu no dia 11 de novembro de 2014, na sede da OAB, em Florianópolis/SC.

Estiveram presentes os representantes estaduais/regionais da OAB, do IBAMA, do MPA, do ICMBio, do Núcleo de Polícia Marítima da Polícia Federal (NEPOM) e da Polícia Militar Ambiental, representantes de associações e colônias de pesca dos municípios de Governador Celso Ramos, São José, Biguaçu e Florianópolis,representantes de prefeituras e câmaras de vereadores destes municípios, pesquisadores da UFPR e analistas ambientais da APAA, da ESEC Carijós, da REBIO Arvoredo e do CEPSUL, totalizando 185 pessoas.

Neste seminário foi brevemente apresentado o histórico da discussão para a proposição de limites à pesca de arrasto na Baía Norte, seguido da apresentação de aspectos sociais, econômicos e ambientais potencialmente decorrentes de cada proposta de limite, fundamentados inclusive nos documentos técnicos elaborados.

Foi então apresentada a realização da pesquisa participante em relação aos dispositivos tecnológicos para a redução da fauna acompanhante (BRDs) na pesca artesanal de arrasto na região, seus resultados parciais e a importância da pesquisa e monitoramento participativo, tanto da pesca de arrasto quanto de 
outras modalidades de pesca e outras atividades humanas, para contribuir na gestão territorial.

Iniciou-se a partir daí o debate, com a palavra aberta, durante o qual as intervenções foram sendo anotadas. A síntese dessas anotações foi sistematizada, durante um intervalo, em forma de carta de intenções sobre o tema, a qual foi, posteriormente, lida e aprovada por unanimidade entre os presentes, tendo sido assinada pelos representantes do IBAMA, do ICMBio e do MPA.

Nesta Carta, descreve-se que "muito embora já existam dados biológicos e socioeconômicos sobre os recursos pesqueiros da região, faz-se necessário o aprofundamento de ações de pesquisa e de monitoramento participativo da pesca, em parceria entre pescadores, unidades de conservação, universidades, órgãos ambientais e centros de pesquisa, visando à correta determinação técnica dos referidos limites, envolvendo as diferentes modalidades de pesca". Com base nesta argumentação, os órgãos que a subscreveram se comprometeram a encaminhar à CTGP a necessidade de formação de um Grupo de Trabalho, em sua esfera, para a definição dos limites da Baía Norte. A carta propõe ainda que, para essa definição, o Grupo de Trabalho deve promover o monitoramento participativo da pesca, "para o que é imprescindível o comprometimento dos pescadores artesanais na busca de alternativas tecnológicas que reduzam o impacto das pescarias".

O documento termina afirmando que "até que sejam definidos, técnica e juridicamente, os limites da pesca na região, para efeito do que dispõe a Portaria SUDEPE ${ }^{\circ} 51 / 83$, fica entendido como limite sul da pesca de arrasto, pelas instituições citadas acima, a linha imaginária formada entre a Fortaleza de Anhatomirim, no continente (coordenadas $27^{\circ} 25^{\prime} 35,70^{\prime \prime}$ s $48^{\circ} 33^{\prime} 48,31$ ”), e o Forte São José da Ponta Grossa, na Ilha de Santa Catarina (coordenadas $27^{\circ} 25^{\prime} 50,15^{\prime \prime}$ s $48^{\circ} 31^{\prime} 08,16$ "o)" (Figura 1).
Este limite coincide com o que vinha sendo considerado pela fiscalização da Polícia Ambiental. Foi proposto um limite "meio termo": aquém da demanda dos pescadores artesanais de arrasto e do proposto pelo plano de manejo da APAA, mas que também não estabelece novas restrições, como proposto pela Nota Técnica do Núcleo de Licenciamento Ambiental do IBAMA. A Coordenação Regional do ICMBio encaminhou formalmente a Carta ao então Secretário de Planejamento e Ordenamento da Pesca do MPA em Brasília, bem como informou a Sede desta Autarquia.

\section{Discussão}

Considerando os recursos ambientais como recursos escassos e distribuídos de forma heterogênea na sociedade, nas últimas décadas tem se proposto diferentes conceitos de "conflito ambiental", visando caracterizar conflitos que envolvem o acesso e utilização de recursos naturais.

Para Ascelrad (2004), "os conflitos ambientais são aqueles envolvendo grupos sociais com modos diferenciados de apropriação, uso e significação do território, tendo origem quando pelo menos um dos grupos tem ameaçada a continuidade de suas formas de apropriação, ameaçada por impactos indesejáveis - transmitidos pelo solo, água, ar ou sistemas vivos em decorrência do exercício das práticas de outros grupos. O conflito pode derivar da disputa por apropriação de uma mesma base de recursos, ou de bases distintas, interconectadas pelas interações ecossistêmicas.” Fundamentalmente, entretanto, qualquer conflito ambiental tem como palco a sociedade, caracterizando-se, antes de tudo, como conflito social.

Tendo em vista a heterogeneidade do meio social, do ambiente e das formas de acesso aos recursos ambientais, a resolução de conflitos é dificilmente alcançada, sendo o processo mais frequente a tentativa de proceder à regulamentação dos mesmos, formando regras e limites aceitos entre os envolvidos (Ostrom, 
1996). A legislação ambiental, assim, consiste na busca da institucionalização dessa regulamentação (Aguiar, 2002).

Essa busca encontra como desafio, entretanto, a geração de regras e limites de fato aceitos entre os envolvidos, especialmente em um país como o Brasil, em que o controle cidadão e a democracia estão ainda em processo de construção e cujo acesso aos recursos naturais tem sido priorizado, por políticas econômicas, aos grupos com maior acesso ao capital (Aguiar, 2002).

Assim, não é comum, na elaboração de instrumentos legais na área ambiental, sequer identificar os envolvidos nos conflitos, quanto mais identificar e discutir regras entre os mesmos. A exclusão social, neste sentido, manifesta-se pela invisibilidade da diversidade social, na qual se insere a diversidade de conhecimentos e valores; dessa forma, os excluídos geralmente nem são candidatos à inclusão social, na medida em que sequer são visíveis (Sousa Santos, 2002).

A edição da Portaria 51, no âmbito da SUDEPE, em 1983, que proíbe áreas para exercício de uma atividade sem definir claramente os limites dessas áreas, tornou vulnerável a atividade de centenas de pescadores artesanais da região, que apesar de invisíveis à elaboração da legislação, têm na atividade a principal fonte de renda. Além disso, apesar de suas boas intenções ecológicas (são óbvios os impactos ao meio ambiente dessa atividade de pesca), não foram objeto de análise da legislação o efeito ambiental de uma eventual substituição de atividade por estes pescadores (dentro ou fora da região), o eventual redirecionamento do uso do território da região para qualquer outra atividade ou grupo social e nem a capacidade de fiscalização da norma. Dessa maneira, além da invisibilidade social, a legislação acabou também desconsiderando os próprios impactos ambientais potenciais de sua aplicação.

Tal abordagem da legislação ambiental tem sido frequente no Estado brasileiro. Offe
(1984) propõe a existência de analogias estruturais entre o Estado e a economia organizada sob forma capitalista, explicitando que o sistema de instituições políticas possui uma seletividade própria, correspondente aos interesses do processo de valorização. Esta seletividade é definida por Bachrach Baratz (1970), citado por Offe (1984), como “a restrição não aleatória (isto é, sistemática) de um espaço de possibilidades". A discussão de Offe pode ser apropriada à legislação ambiental, em diferentes contextos (Steenbock, 2009).

Offe (1984) propõe que, nas instituições públicas, a citada seletividade se dá a partir de quatro filtros sobrepostos: estrutura, ideologia, processo e repressão.

O filtro da estrutura está relacionado com o âmbito de ação de cada instituição e suas capacidades de influência. No nível do filtro ideológico, o autor coloca que "existe algo como uma ideologia não articulada nas instituições públicas, mesmo naquelas que parecem ser mais abertas, flexíveis e assistemáticas uma ideologia no sentido de promover a percepção e articulação seletiva de problemas e conflitos sociais".

O nível do filtro de "processo" se constitui no estabelecimento de procedimentos institucionalizados de formulação e implementação política que conferem a "certos conteúdos políticos probabilidades de realização maiores, assegurando tratamento preferencial a certos interesses, concedendo-lhes prioridade no tempo, oportunidades de coalizão mais favoráveis ou a possibilidade de aplicação de meios de poder específicos". Associado a este direcionamento, está implícito o conceito de "não decisão", caracterizado como um "instrumento pelo qual reivindicações para a mudança na alocação de benefícios e privilégios podem ser sufocadas antes que tenham sido expressas; ou mantidas latentes; ou eliminadas antes que acedam a arena decisória relevante; ou, falhando tudo isso, mutiladas ou destruídas no estágio da implementação da decisão" (Bachrach 
Baratz, 1970, citado por Offe, 1984).

O nível do filtro da "repressão" representa o último filtro, aplicado quando os demais falham, e é representado pela aplicação ou ameaça de atos repressivos do aparelho estatal por meio dos órgãos de polícia, exército ou justiça (Offe, 1984).

O texto da Portaria SUDEPE ${ }^{\circ} 51 / 83$, ao proibir pesca de arrasto em baías, pressupõe, ideologicamente, que qualquer arrasto, em qualquer baía de Santa Catarina, é danoso àquele ambiente e, por consequência, ao ambiente como um todo, desconsiderando, em determinadas situações, a complexidade da questão em cada território. Tal arcabouço ideológico permeia, em parte, a estrutura dos órgãos ambientais, cuja atuação e equipagem tem se centrado historicamente na tentativa de redução de problemas ambientais, sem necessariamente considerar que tais problemas estão inseridos em um universo social, econômico e cultural. Recentemente, entretanto, diversas iniciativas vêm colocando essa complexidade em discussão na elaboração de instrumentos legais, como é o caso da permissão de um determinado tipo de arrasto (gerival) na Baía da Babitonga, também em Santa Catarina, a partir do cumprimento de vários critérios e limitações (Portaria IBAMA no 84/02, Brasil, 2002b), bem como da elaboração de Termos de Compromisso entre populações tradicionais e unidades de conservação de proteção integral, no âmbito do ICMBio.

O "filtro de processo", caracterizado por Offe (1984), está refletido na consideração, por parte dos órgãos ambientais, da região em questão como uma baía, desde 1983, embora possam ser questionadas a motivação técnica, científica ou cultural que assim a definisse, e, por sua vez, nas próprias incertezas nestes 30 anos, de onde seriam seus limites, causando inseguranças na realização das operações de pesca.

O “filtro da repressão", neste caso, é inerente à prática da fiscalização da pesca na região, realizada pelos mesmos órgãos; ou seja, durante 30 anos, autuações foram procedidas, considerando a pesca em uma baía, embora sem limites claros definidos.

Considerando o exposto, é importante mudar a prática do direito como um ordenamento repressivo (que existe, é inegável), para conceber o direito também com um papel promotor, mediante técnicas de estímulo: no papel repressivo, interessam ao direito os comportamentos socialmente indesejados, e então a função primordial do direito é impedir que se realizem; no papel promotor, interessam os comportamentos socialmente desejados e, para tanto, o direito busca provocar sua prática, também entre os recalcitrantes. Como repressor, o direito impede coercitivamente os comportamentos indesejados; como promotor, o direito estimula os comportamentos socialmente desejados. No fundo, para além de uma função, essa visão do direito é uma técnica de regulamentação de comportamentos e de consecução de objetivos que estimula e promove as condutas consideradas socialmente úteis (Galiana, 2003).

A APAA considerou socialmente útil fomentar a regulação à prática do arrasto, pelos possíveis recalcitrantes inclusive, numa área socialmente pactuada, tendo em vista a importância econômica, cultural e social da atividade, bem como a necessidade de melhor conhecer as bases ecológicas do território em questão.

Nesse contexto, do ponto de vista teórico, vale a pena aproveitar algumas considerações do sociólogo alemão Niklas Luhmann (1927-1998), acerca da concordância social com premissas e com tomadas de decisão, de forma distinta.

Algumas premissas, como o direito ao sustento próprio e da família, o uso ecologicamente equilibrado dos recursos e sua preservação, a necessidade de manter os estoques pesqueiros, a importância financeira, cultural e social da pesca artesanal na região, além de 
outras, são premissas facilmente aceitáveis, em princípio. O problema está na tomada de decisão a partir das premissas, pois esta implica numa aceitação e, portanto, em um comportamento correspondente. Quais as premissas da Portaria SUDEPE ${ }^{\circ} 51 / 83$ ? A julgar pelo Relatório da quarta reunião, (reunião que motivou esta Portaria, como mencionado no início da Introdução), alguém poderia entendê-las relacionadas, exclusivamente, aos ambientes lagunares e ao impacto no camarão-rosa pela pesca, e então não reconhecer como legítima a decisão tomada (a regra como saiu portariada). No conceito de legitimidade, é importante distinguir a concordância com as premissas de uma decisão e a concordância com a própria decisão. O reconhecimento de uma norma pode-se dar por sua aceitação como obrigatória, mas também pela aceitação de suas premissas. Não aceitas as premissas, por quaisquer razões, individual ou coletivamente, o embate é inevitável (Luhmann, 1980).

O que a APAA buscou foi o consenso quanto às premissas e ela o promoveu, ou pelo menos tornou-o oportuno, observando a existência do tema (o problema do limite do arrasto existia, mas não se debatia), o momento de trazê-lo à discussão (no plano de manejo e especialmente quando se tratou de extrapolar os limites da unidade) e o potencial de apoio político ("político" no sentido originário, de polis como espaço de convivência que exige acordos entre os atores) (Luhmann, 1980).

Nesse sentido, o Plano de Manejo da APAA, como produto de um processo de diagnóstico e planejamento participativo, possibilitou maior envolvimento social na discussão e definição de normas de ordenamento territorial, nas quais a definição do limite para pesca artesanal de arrasto de camarões está inserida. Entretanto, este processo não ocorreu, com a mesma magnitude, fora dos limites da própria APAA, na medida em que não houve a construção de um plano de ordenamento territorial semelhante ao do Plano de Manejo na região como um todo. Assim, a elaboração participati- va e com forte envolvimento institucional de um Plano de Manejo é, ao mesmo tempo, uma oportunidade e um desafio: oportunidade, no sentido de buscar agregar, de forma ampla e legítima, conhecimentos, opiniões e posições frente à necessidade do estabelecimento de regras e do zoneamento territorial; desafio, no sentido de se buscar a integração desta agregação para além dos limites territoriais da Unidade de Conservação, visto que os recursos, as paisagens e os ecossistemas, bem como as instituições e os atores sociais, tendem a extrapolar os seus limites.

De qualquer forma, desde 2009, com a lei da pesca, a sustentabilidade deve reger-se pelos objetivos da permanência e da continuidade do pescador artesanal, condição que se impõe ao ordenamento pesqueiro, devendo para tanto ser consideradas as peculiaridades e as necessidades dos pescadores artesanais, de subsistência e da aquicultura familiar ( $\S 1^{\circ}$ do artigo $3^{\circ}$ da lei 11.959/2009 - Brasil, 2009a). Muito embora a não atualização de algumas normas antigas, muitos gestores não consideram, em sua prática de gestão atual, os objetivos definidos na lei da pesca, talvez por recusarem aceitar as premissas, entre as quais o desafio do direito promotor de comportamentos socialmente desejáveis, remetendo à discussão baseada em Galiana (2003) e em Luhman (1980), acima, e ao filtro da "ideologia", proposto por Offe (1984).

No caso em tela, o acúmulo de discussões entre os pescadores da APAA e dos posicionamentos de órgãos de fiscalização ambiental, da academia e de direitos difusos foi suficiente para o ordenamento da pesca de arrasto dentro da APAA, carecendo, entretanto, de ampla legitimidade fora dela.

Quando a definição do limite geográfico para a pesca artesanal de arrasto de camarões foi novamente questionada, fora dos limites da APAA, as referências possíveis para o seu estabelecimento envolveram parâmetros geográfi$\cos$ (detalhados na Nota Técnica $n^{0}$ 
02026.000007/2014-72, do Núcleo de Licenciamento Ambiental do IBAMA/SC), parâmetros ecológicos (detalhados no Documento Técnico $n^{0}$ 138/2014, da ESEC Carijós e no Plano de Manejo da APAA) e parâmetros de gestão, definidos no próprio Plano de Manejo da APAA e indicados na Nota Técnica da ESEC Carijós. Porém, a esfera de ordenamento territorial, neste ambiente, cabia ao MPA e MMA, tendo como órgão consultivo e coordenador das atividades do sistema de gestão compartilhada a CTGP, instituída para assessorar as decisões daqueles ministérios (Decreto $\mathrm{n}^{\circ}$ 6.981/o9 Brasil, 2009b), e não à APAA ou a qualquer outra instituição de âmbito local ou regional. Cabe ressaltar que o MPA foi extinto em outubro de 2015, sendo sua ação executiva e de ordenamento em princípio recepcionada pelo Ministério da Agricultura, Pecuária e Abastecimento (MAPA), até que sejam elaborados outros instrumentos legais, provavelmente gerando nova onda de instabilidade institucional na gestão do uso dos recursos pesqueiros.

Os parâmetros citados puderam fundamentar a solicitação de uma análise da questão pela CTGP. Cabe ressaltar, todavia, que tal comissão não tem sido eficiente para a análise e gestão de todas as demandas a ela direcionadas, mesmo em âmbito nacional, gerando pouquíssimos resultados de ordenamento em nível local. Essa pouca eficiência tende provavelmente a ficar ainda menor, com a extinção do MPA.

A ineficácia de gestão atual do uso dos recursos pesqueiros não evita a continuidade das atividades pesqueiras, mas a dependência de tomada de decisões a partir da CTGP, de acordo com o atual modelo delineado, dificulta o estabelecimento de outros fóruns de gestão, tão necessários para o adequado ordenamento da pesca em nível local e territorial.

A solução encontrada em relação aos limites da Baía Norte de Florianópolis foi, a partir da mobilização dos pescadores, gerar um processo de discussão amplo e um comprometimento, por parte dos órgãos de fiscalização, em assumir uma postura única, ainda que temporária, quanto ao limite em questão. Assim, de certa forma, a dificuldade de análise e proposição de medidas pela CTGP em função da centralização de resolução de inúmeras demandas, possibilitou, por outro lado, o estabelecimento de um acordo envolvendo os pescadores e estas instituições, contando com a ampla participação dos envolvidos.

O processo de discussão e de comprometimento em tela traz à tona a possibilidade da visibilização de um conflito como um caminho não só para a institucionalização de sua regulamentação, mas para o estabelecimento de espaços de gestão territorial com participação social, visando a efetivação do papel promotor do Direito (Galiana, 2003).

Dessa forma, o conflito, quando visibilizado, traz em si o atributo de promover a discussão entre diferentes atores sociais, o que demanda busca de argumentações de ordem técnica, científica, cultural, social e econômica, bem como de espaços de debates e interações dessas argumentações, utilizados como fóruns de prática da participação social e da cidadania. Essa perspectiva se aproxima à abordagem sociológica que Georg Simmel (1858-1919) faz do conflito. Na perspectiva simmeliana, o conflito tem o atributo positivo de criar um tablado social, como se fora um palco teatral, um espaço onde as partes conflitantes podem se encontrar em um mesmo plano situacional e, desta maneira, gerar um nivelamento. Dessa forma, é possível para as partes, "por vezes ásperas e díspares”, efetuar a trama que o conflito encerra. Assim, o conflito possui a capacidade de constituir-se num espaço social, em que o próprio confronto é um ato de reconhecimento e, ao mesmo tempo, produtor de um metamorfismo entre as interações e as relações sociais daí resultantes” (Simmel, 1983).

Neste "palco", um aspecto importante a ser considerado é a relação entre a visibilização do conflito, as bases técnicas e científicas que podem contribuir na sua gestão, a participação 
e a legitimidade dos atores envolvidos e a préexistência de normas de ordenamento (motivadas a partir de demandas contextualizadas em outro momento histórico, político e de ordenamento territorial). A gestão do conflito exige o exercício político e social destes elementos para o metamorfismo citado por Simmel e, no que tange à institucionalização de acordos relacionados ao uso do ambiente e de recursos naturais, a promoção de instrumentos que sejam implementados no sentido da conservação socioambiental.

No processo de discussão e deliberação do acordo resultante do processo descrito neste trabalho é importante destacar o papel da existência de um projeto de pesquisa participante, junto aos pescadores, visando reduzir o impacto ambiental deste tipo de pescaria. O Acordo foi condicionado "ao aprofundamento de ações de pesquisa e de monitoramento participativo da pesca, em parceria entre pescadores, unidades de conservação, universidades, órgãos ambientais e centros de pesquisa, visando à correta determinação técnica dos referidos limites, envolvendo as diferentes modalidades de pesca”.

O monitoramento participativo da biodiversidade, portanto, foi percebido pelos envolvidos no Acordo para além dos resultados de pesquisa, como um processo fundamental de gestão territorial, e pode representar um elo fundamental para o exercício político e social entre os elementos citados acima. Neste sentido, a experiência da construção deste Acordo pode se constituir em uma referência importante para a gestão territorial em unidades de conservação, além da reflexão dos limites e possibilidades das mesmas como instrumentos de gestão pesqueira.

\section{Referências bibliográficas}

ABLE, K. W. 2005. A re-examination of fish estuarine dependence: Evidence for connectivity between estuarine and ocean habitats. Estuarine, Coastal and Shelf Sci- ence, 64: 5-17.

ACSELRAD, H. 2004. Conflitos Ambientais: a atualidade do objeto. In ACSELRAD, Henri, Conflitos Ambientais no BRASIL. Rio de Janeiro, Relume Dumara.

AGUIAR, R. A. R. 2002. Direito do meio ambiente e participação popular. Brasília, DF, Publicações IBAMA.

BRASIL, 1983a. Portaria SUDEPE n ${ }^{\circ} \mathrm{N}-51$, de 26 de outubro de 1983. Diário Oficial [da] União, Brasília, DF, 28 out. 1983.

BRASIL, 1983b. Relatório da IV Reunião do Grupo Permanente de Estudos Sobre Camarões: Santos-SP, Setembro de 1983. Brasília, DF, SUDEPE/IPDP, 85 p.

BRASIL, 1992. Decreto ${ }^{0} 528$, de 20 de maio de 1992. Declara como Área de Proteção Ambiental Anhatomirim, no Estado de Santa Catarina, a região que delimita e dá outras providências Diário Oficial [da] União, Brasília, DF, 20 maio. 1992.

BRASIL. 2000. Lei $n^{0}$ 9985, de 18 de julho de 2000. Regulamenta o art. 225, § 10, incisos I, II, III e VII da Constituição Federal, institui o Sistema Nacional de Unidades de Conservação da Natureza e dá outras providências. Diário oficial [da] união, Brasília, DF, 19 jul. 2000.

BRASIL, 2002a. Decreto $n^{0}$ 4340. de 22 agosto de 2002. Regulamenta artigos da Lei $n^{0}$ 9.985, de 18 de julho de 2000, que dispõe sobre o Sistema Nacional de Unidades de Conservação da Natureza - SNUC, e dá outras providências. Diário Oficial [da] União, Brasília, DF, 22 ago. 2002.

BRASIL, 2002b. Portaria IBAMA no 84, 15 de julho de 2002. Diário Oficial [da] União, Brasília, DF, 16 jul. 2002.

BRASIL, 2009a. Lei no 11.959, de 29 de junho de 2009. Dispõe sobre a Política Nacional de Desenvolvimento Sustentável da Aquicultura e da Pesca, regula as atividades pesqueiras, revoga a Lei $n^{0} 7.679$, de 23 de no- 
vembro de 1988, e dispositivos do DecretoLei $\mathrm{n}^{\circ}$ 221, de 28 de fevereiro de 1967, e dá outras providências. Diário Oficial [da] União, Brasília, DF, 30 jun. 2009.

BRASIL, 2009b. Decreto $\mathrm{n}^{\circ}$ 6.981, de 13 de outubro de 2009. Regulamenta o art. 27, § $6^{\circ}$, inciso I, da Lei $\mathrm{n}^{\mathrm{o}}$ 10.683, de 2003, dispondo sobre a atuação conjunta dos Ministérios da Pesca e Aquicultura e do Meio Ambiente nos aspectos relacionados ao uso sustentável dos recursos pesqueiros. Diário Oficial [da] União, Brasília, DF, 14 de out. de 2009.

BRASIL, 2010. Plano de manejo da Estação Ecológica de Carijós. Instituto Chico Mendes de Conservação da Biodiversidade (ICMBio).

BRASIL. Instituto Chico Mendes de Conservação da Biodiversidade. 2013. Plano de manejo da Área de Proteção Ambiental do Anhatomirim. Florianópolis, SC, S.n,.

BRASIL, 2014. Estação Ecológica de Carijós. Documento Técnico $\mathrm{n}^{0}$ 138, de 22 de outubro de 2014.

GALIANA, A. S. 2003. La legislación en el estado de derecho. Madrid, Dikinson. 132p.

LUHMANN, N. 1980. Legitimação pelo procedimento. Tradução de Maria da Conceição Corte-Real. Brasília, DF, Universidade de Brasília.

OFFE, C. 1984. Problemas estruturais do Estado capitalista. Rio de Janeiro, Tempo Brasileiro.

OSTROM, E. 1996. Governing the commons: The evolution of institutions for collective action. 8. ed. New York, Cambridge University Press.

PORTELLA, G. D. G. 2015. Modificações tecnológicas nas redes de arrasto de camarões: implicações e aplicações para gestão em uma área marinha protegida. Curitiba, 38 p. (Dissertação de Mestrado, Mestrado em Sistemas Costeiros e Oceânicos, Universi- dade Federal do Paraná).

SOUSA SANTOS, B. 2002. Produzir para viver: os caminhos da produção não capitalista. Rio de Janeiro, Civilização Brasileira.

SIMMEL, G. 1983. Sociologia. Organizador Evaristo de Moraes Filho. Introdução de Carlos Alberto Pavanelli. São Paulo, Ática.

STEENBOCK, W. 2009. Domesticação de bracatingais: perspectivas de inclusão social e conservação ambiental. Florianópolis, 281 p. (Tese de Doutorado, Programa de PósGraduação em Recursos Genéticos Vegetais da Universidade Federal de Santa Catarina).

VESSAZ, F. 2014 Human dimensions of bycatch in small-scale shrimp trawl fisheries: implications for bycatch reduction devices in southern Brazil. Pontal do Paraná. 45 p. (Dissertação de Mestrado. Marine Biodiversity and Conservation. EMBC). 